\title{
La guerra contra el terrorismo y el estado de derecho*
}

Este comentario, junto a los documentos que analiza, está disponible en www.anuariocdh.uchile.cl

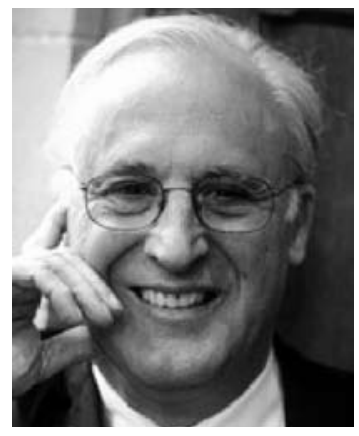

\section{Owen M. Fiss}

Profesor Sterling de Derecho, de la Univesidad de Yale, LL.B de Harvard (1964), B. Phil., Oxford (1961) y B. A., Darmouth (1959). Fue asistente (clerck) de Thurgood Marshall (cuando Marshall fue juez de la Corte de Apelaciones del Segundo Circuito de Estados Unidos) y posteriormente de William J. Brennan, Jr., juez de la Corte Suprema. También trabajó en la División de Derechos Civiles del Departamento de Justicia. Antes de trabajar en la Universidad de Yale, impartió clases en la Universidad de Chicago.

owen.fiss@yale.edu

\section{RESUMEN}

La guerra contra el terrorismo -expresión política que se ha empleado para movilizar a la sociedad estadounidense hacia sucesivas guerras después de los ataques del 11 de septiembre- ha tenido consecuencias especialmente gravosas para Estados Unidos, pero muy especialmente para la Constitución y el imperio del derecho. En este artículo se revisan las políticas y prácticas que han puesto en entredicho el imperio del derecho en temas tan vitales y sensibles como la prohibición de la tortura, la privacidad de las comunicaciones entre privados, el debido proceso y las garantías procesales.

La expresión "guerra contra el terrorismo" no tiene un contenido legal determinado . Fue acuñada por motivaciones políticas y empleada por el gobierno del Presidente Bush para movilizar a la sociedad estadounidense. No obstante, la declaración de la guerra contra el terrorismo dio origen a una etapa única en el derecho estadounidense que comenzó el 11 de septiembre del 2001 y continúa hasta el día de hoy. Es una etapa en la que ha estado en duda el compromiso de los Estados Unidos respecto del imperio del derecho.

Si bien la guerra contra el terrorismo no es una guerra propiamente tal, en los siete años que han transcurrido desde que se declaró, Estados Unidos ha emprendido tres guerras. Una se lleva a cabo en Irak. El terrorismo no fue el fundamento de nuestra decisión para invadir dicho país, sino que más bien ha surgido como una consecuencia de la guerra y del régimen de ocupación del país que inevitablemente se produjo luego de la invasión. Cuando Estados Unidos invadió Irak en

\footnotetext{
* El presente artículo fue traducido del inglés por Jennifer Ann Metcalfe y revisado y editado por José Zalaquett y Claudia Sarmiento.

1 Este artículo fue redactado durante el segundo semestre de 2008.
} 
marzo del 2003, el gobierno no tenía evidencia de que Saddam Hussein hubiera patrocinado los ataques terroristas del 11 de septiembre del 2001 y hasta la fecha siguen sin encontrarse pruebas en tal sentido. Sin embargo, como el mismo gobierno ha señalado, numerosas organizaciones terroristas han aprovechado el caos político existente en el Irak ocupado para llevar a cabo ataques violentos en contra de soldados estadounidenses y ciudadanos iraquíes.

La segunda guerra -la invasión de Afganistán en octubre del 2001- tenía una conexión directa e inmediata con los acontecimientos del 11 de septiembre. El gobierno estadounidense estableció que Al Qaeda era la organización responsable de los ataques cometidos ese día y, además, que el régimen Talibán que dominaba a Afganistán en ese momento tenía una relación especial -es más, una relación simbiótica- con Al Qaeda. Esta última organización había ayudado al régimen Talibán a acceder al poder y, a cambio, los talibanes habían albergado y protegido a Al Qaeda. Cuando los talibanes se negaron a capturar o a entregar a los líderes de AI Qaeda, Estados Unidos invadió el país.

La tercera guerra -la guerra contra Al Qaeda propiamente tal- es la que la mayoría de nosotros tiene mayores dificultades para considerar como una guerra, fundamentalmente porque Al Qaeda no constituye una nación con límites geográficos definidos. Es una organización internacional que opera en forma clandestina. Sin embargo, de manera muy similar a un país enemigo, ha declarado que su objetivo es matar estadounidenses en forma masiva, independientemente de dónde se encuentren -sea en Kenia, Tanzania, Nueva York, Washington, Kabul, o Bagdad. El propósito de tales matanzas no es claro; las justificaciones expresadas abarcan desde la presencia de bases militares estadounidenses en Arabia Saudita y el respaldo a Israel por parte de Estados Unidos, hasta la supuesta naturaleza depravada de la civilización estadounidense. Sin embargo, para el gobierno estadounidense no fue necesario descubrir un propósito claro detrás de las acciones de Al Qaeda o determinar que esta organización buscaba derrocarlo para tratarla como beligerante.

En los últimos siete años hemos logrado -en gran medida mediante el poder de las armas- limitar la capacidad de Al Qaeda de atacar a estadounidenses, pero no hemos logrado eliminar completamente la amenaza del terrorismo que dicha organización genera. En consecuencia, Estados Unidos sigue estando claramente en guerra contra Al Qaeda y es esta guerra -incluso más que la invasión y ocupación de Irak y la presencia estadounidense en Afganistán- lo que sigue aportando vigor a la guerra contra el terrorismo y que plantea el desafío más agudo del compromiso de Estados Unidos frente al imperio del derecho.

Al referirme al imperio del derecho, estoy hablando de las normas de la Constitución y las leyes, y no al cuerpo más amplio de disposiciones reglamentarias. Este último está formado por decretos, normas y reglamentos emitidos por agencias y funcionarios de gobierno. A veces, tales disposiciones instruyen a los funcionarios públicos acerca de la forma en la cual deben cumplir sus obligaciones. En otras instancias (por ejemplo en el caso del Código de Impuestos Internos) dichos decretos están dirigidos a los ciudadanos en general. A menudo, la guerra requiere que se ajusten estas regulaciones, o se dicten otras nuevas para permitir al Estado enfrentar al enemigo.

La guerra implica un peligro mayor para la Constitución que para tales regulaciones. Como encarnación de la ética pública de la nación, la Constitución no se limita a las palabras contenidas en el documento redactado en 1787, ni en las 27 reformas constitucionales promulgadas formalmente en los pasados 220 años. La Constitución incluye principios -como por ejemplo, la separación de poderes o el derecho de desplazarse libremente de un estado de la Unión a otro- que se infieren de la estructura general de la Carta Fundamental. El alcance de la Constitución también abarca las leyes aprobadas por el Congreso, que extienden los valores contenidos en el texto original. Por ejemplo, la Ley de Derechos Civiles de 1964, ha dado un contenido más acabado al concepto 
"igualdad ante la ley", contenido en la Constitución. Entendida en este sentido más amplio, la Constitución conlleva un valor normativo especial que se deriva del papel que desempeña en la definición de nuestra identidad nacional -a saber, lo que significa ser estadounidense- y en la articulación de los principios que rigen nuestra sociedad.

La guerra somete a la sociedad a grandes tensiones. Requiere de ajustes mayores a nivel de gobierno y en la vida cotidiana. A menudo, se necesita que la gente realice sacrificios enormes. En respuesta a dichas necesidades, con frecuencia se modifican las normas: el Poder Ejecutivo promulga nuevos reglamentos y el Congreso aprueba nuevos cuerpos jurídicos para hacer frente a las exigencias de la guerra. Sin embargo, el supuesto predominante de la sociedad estadounidense es que estas medidas relacionadas con la guerra se adoptarán dentro de los términos señalados en la Constitución: que se observará la asignación de poderes entre las distintas ramas establecidas en la Constitución y que se respetarán las libertades fundamentales. Nuestra Constitución rige tanto en tiempo de guerra, como en tiempos de paz.

Los últimos siete años han perturbado este supuesto y lamentablemente dejan en evidencia la fragilidad del imperio del derecho. Aunque parezca increíble, la guerra contra el terrorismo ha llegado a socavar un principio tan sacrosanto como la prohibición de la tortura. En virtud de un programa denominado rendición extraordinaria, personas que son sospechosas de tener vínculos con Al Qaeda han sido secuestradas por funcionarios estadounidenses y trasladadas en secreto a países que habitualmente ejercen la tortura como parte de sus técnicas de interrogatorio, tales como Siria y Egipto. Al entregar a las personas a países en los cuales es probable que se les torture, nuestro gobierno es tan culpable como si hubiera Ilevado a cabo la tortura directamente. Los juicios presentados en Estados Unidos por algunas de estas víctimas fueron desestimados sumariamente por los tribunales federales inferiores. Los jueces estimaron que cualquier investigación respecto del mérito de las acusaciones podría comprometer la conducción del Presidente en cuanto a las relaciones exteriores y las operaciones militares y, como tal, serían incoherentes con la deferencia que se le debe a su cargo.

Los memorándum internos de la administración, filtrados después de que en mayo de 2004 salieran a la luz los abusos cometidos en contra de los prisioneros confinados en Abu Ghraib (Irak), revelaron una indolencia similar en cuanto a la prohibición en contra de la tortura. El objetivo fundamental de estos memorándum era precisar la definición de tortura con el fin de ampliar la gama de técnicas que los encargados de la interrogación podían utilizar contra los prisioneros que pudieran tener información acerca de AI Qaeda. Un memorándum de agosto del 2002, emitido por el Departamento de Justicia, señalaba que causar dolor físico equivalía a tortura solamente cuando era "equivalente en su intensidad al dolor que implica un grave daño físico, como por ejemplo la falla de un órgano o de funciones corporales, o incluso la muerte". Otro memorándum, emitido por el Departamento de Defensa sólo unos pocos meses después, establecía las pautas para los interrogatorios realizados en la Base Naval de la Bahía de Guantánamo. Sugería que dos métodos que hasta la fecha eran universalmente considerados técnicas propias de la tortura -la utilización de determinados puestas en escena diseñadas para hacer creer a los detenidos que su muerte era inminente y el uso de una toalla mojada con goteo constante para inducir el temor de morir ahogado ("water-boarding")-, a pesar de estar prohibidos, no obstante "se pueden utilizar legalmente" como una "cuestión de política en las presentes circunstancias".

Estos memorandos internos no sólo intentaban disminuir la fuerza de la prohibición en contra de la tortura mediante una ampliación de las conductas permitidas, sino que iban más allá e implicaban que tal prohibición no se aplicaba en lo absoluto a la lucha emprendida por el Presidente en contra de Al Qaeda. El memorando del Departamento de Justicia de agosto del 2002 consideró la prohibición contra la tortura simplemente como un asunto de regulación, negando, de 
esa manera, que fuese vinculante para el Presidente en su calidad de Comandante en Jefe. El memorando argumentaba que el Congreso carecía de facultades para intervenir en la forma en que el Presidente ejecuta sus deberes constitucionales.

En diciembre del 2004, el Departamento de Justicia publicó un memorando que dejaba sin efecto la artificiosa definición de tortura establecida en su memorando del año 2002. El documento de diciembre no renegaba de la anterior afirmación en el sentido de que el Presidente estaba facultado para autorizar la tortura, sino que manifestaba que era "innecesario" abordar el tema porque el Presidente ya había -luego de las revelaciones sobre Abu Ghraib y la divulgación del memorando anterior- emitido una directriz instruyendo al personal estadounidense que no realizara actos de tortura.

En la Ley de Trato de los Detenidos del año 2005, el Congreso reguló la prohibición sobre la tortura que establece la Constitución. El Presidente resistió ferozmente la medida y, si bien finalmente firmó la ley para su promulgación, lo hizo junto con una declaración de que se proponía interpretar la ley como un cuerpo legal coherente con sus atribuciones constitucionales como Comandante en Jefe de las Fuerzas Armadas y su obligación de proteger a la nación contra futuros ataques terroristas. Esta declaración fue ampliamente interpretada como una indicación de que el Presidente no se consideraba limitado por los términos de dicha Ley. El Presidente tenía toda la razón en cuanto a que ciertas normas constituyen simplemente regulaciones que no pueden interferir con sus atribuciones constitucionales como Comandante en Jefe. No obstante, el caso de la prohibición legal de la tortura es distinto, porque especifica un principio constitucional fundamental establecido en la Quinta y en la Octava Enmienda que es superior a las facultades del Presidente como Comandante en Jefe de las Fuerzas Armadas.

Un segundo principio constitucional que se ha visto amenazado por la guerra contra el terrorismo de Estados Unidos, es el derecho de la gente de comunicarse libremente entre sí, sin temer que el gobierno esté escuchando sus conversaciones en forma clandestina. Esta libertad está garantizada por la Cuarta Enmienda pero, a diferencia de la libertad que emana de la prohibición contra la tortura, no constituye un derecho absoluto ya que solamente está prohibida la invasión "no razonable" de la privacidad. Sin embargo, históricamente el Poder Judicial ha protegido el derecho de la gente de hablar libremente al exigir que el gobierno -en la medida de lo posible- obtenga una orden judicial otorgada por un tribunal antes de intervenir conversaciones privadas. La obligación para el gobierno de formular sus fundamentos ante un juez independiente sirve para limitar los excesos del Poder Ejecutivo y, de esta manera, protege nuestra libertad.

El Presidente no estaba dispuesto a someterse a esta norma en su persecución de AI Qaeda. En el año 2005, los medios de comunicación revelaron que, poco tiempo después de los ataques del 11 de septiembre, el Presidente autorizó que la Agencia Nacional de Seguridad (NSA) interceptara comunicaciones entre personas que se encontraban en Estados Unidos y otras que estaban en el extranjero si la NSA pensaba que una de las partes estaba vinculada a AI Qaeda. Estas grabaciones telefónicas se llevaron a cabo sin orden ni supervisión judicial.

Por deferencia al Presidente en asuntos de seguridad nacional, la Corte Suprema se ha mostrado renuente a aplicar a la intervención de teléfonos del tipo que se realiza bajo el programa de la NSA el requisito de contar con una orden judicial que establece la Cuarta Enmienda. Hace aproximadamente unos 40 años -en 1967- la Corte Suprema determinó que la intervención de teléfonos era una forma de allanamiento y que, en consecuencia, debía regirse por el requisito de orden judicial establecido en la Cuarta Enmienda. Junto con llegar a esta conclusión, la Corte Suprema se cuidó de precisar la situación que estaba examinando - un proceso contra una banda 
de apuestas ilegales- y distinguirla de la vigilancia que se efectúa con fines de seguridad nacional, rehusando referirse a este último tema.

En el año 1972, a medida que las protestas en contra de la guerra de Vietnam se volvieron más turbulentas, la Corte Suprema amplió el requisito de la orden judicial a lo que denominó "situaciones de seguridad interna". El caso específico que estaba viendo la Corte era el procesamiento de una persona considerada sospechosa de haber hecho estallar una oficina de la CIA en Ann Arbor, Michigan. De nuevo, la Corte explícitamente dejó sin resolver el hecho de si las órdenes judiciales serían un requisito para la vigilancia contra poderes extranjeros y, hasta ahora, no ha fallado al respecto.

En el año 1978, el Congreso intentó cubrir este vacío mediante la promulgación de la Ley de Vigilancia de Inteligencia Extranjera (FISA). Esta ley prohíbe que el gobierno intercepte cualquier comunicación entre poderes extranjeros y una persona que se encuentra en Estados Unidos -incluso la vigilancia para fines de seguridad nacional- sin la autorización de un tribunal especial. Los jueces de dicho tribunal son elegidos por el Presidente de la Corte Suprema de EE.UU.; se reúnen en secreto; el sujeto de la intervención telefónica no recibe notificación alguna de la solicitud del gobierno; la decisión del tribunal se emite sobre la base de los documentos presentados por el gobierno; y este último puede imponerse demostrando que la interceptación probablemente conducirá a obtener información de inteligencia sobre asuntos exteriores que, razonablemente, no se puede obtener por otros medios.

Desde su promulgación la FISA ha sido considerada como un marco integral para la captación de datos de inteligencia extranjera del tipo que implica el Programa NSA. En su defensa inicial de dicho programa, el Procurador General de Justicia afirmó, de manera poco convincente, que la resolución del Congreso que permitía el uso de la fuerza en contra del terrorismo autorizaba, implícitamente, los allanamientos sin necesidad de contar con una orden judicial. Sin embargo, dicho argumento se vio eclipsado por la afirmación más audaz del Procurador General en el sentido de que someter al Presidente a los requisitos de la FISA afectaría de manera inconstitucional su autoridad para llevar a cabo la guerra contra AI Qaeda.

El Procurador General reconoció que el Congreso tiene poderes en materias relacionadas con la guerra: puede declarar la guerra, aprobar regulaciones generales respecto de las fuerzas armadas y asignar fondos para las mismas. Sin embargo, el Procurador General sostuvo que la intervención de los teléfonos realizada por la NSA debía ser vista de manera similar a cualquier otro enfrentamiento estratégico con el enemigo y que, en tanto tal, estaba dentro de los poderes del Presidente en su calidad de Comandante en Jefe.

A pesar de que la postura del Procurador General planteó preguntas importantes acerca de la distribución de poderes entre el Congreso y el Presidente, dicha controversia fue superada por hechos posteriores. En enero del 2007, el Procurador General anunció que el Presidente, en ejercicio de sus facultades discrecionales, no renovaría la autorización para este programa de intercepción de comunicaciones sin control judicial. A continuación, el Presidente se dirigió al Congreso y recibió, primero en agosto de 2007 y nuevamente en junio de 2008, el otorgamiento de amplias facultades que deseaba obtener.

La ley adoptada en junio del 2008, que permanecerá vigente hasta el 2012, modificó la FISA permitiendo que se intervinieran teléfonos sin requerir supervisión judicial alguna si el Procurador General y el Director de Seguridad Nacional certifican que existen razones para estimar que el objeto de dicha vigilancia tiene vinculaciones con el terrorismo. Las personas cuyas comunicaciones son objeto de intercepción debe encontrarse fuera de los Estados Unidos, pero la grabación puede aplicarse a conversaciones telefónicas con personas que se encuentren en Estados Unidos. 
Asimismo, el estatuto otorga inmunidad a todas las empresas que proporcionan servicios de telecomunicaciones que colaboren con dichas intervenciones telefónicas, incluso aquellas que habían colaborado con la NSA antes de la promulgación de esta ley.

La ley del año 2008 torna irrelevante cualquier objeción a la intervención telefónica sin orden judicial que se base en la separación de poderes; pero subsiste la objeción basada de la Cuarta Enmienda, porque dicha norma es superior a cualquier pretensión que pudiera tener el Presidente en su calidad de Comandante en Jefe y no puede ser modificada por el Congreso. Si bien la Corte Suprema se ha negado a manifestarse sobre el particular, los fundamentos que la indujeron a imponer el requisito de la orden judicial tanto en casos criminales ordinarios, como en los casos de seguridad nacional, se aplican de igual manera a la intervención telefónica del tipo establecido en el Programa NSA. El requisito de la orden judicial no impide que el Presidente descubra actividades criminales, ni tampoco lo imposibilita para evitar actos de terrorismo, sino solo requiere que el mandatario plantee la situación ante un juez independiente, como una forma de reducir al mínimo los abusos y evitar el menoscabo de la libertad de comunicación que se produciría si el Presidente estuviera autorizado para intervenir el teléfono de cualquier persona que estime que tiene vínculos con Al Qaeda.

Un tercer principio -lo que denomino el principio de libertad-también ha sido violado durante la guerra contra el terrorismo. Este principio está arraigado en la garantía constitucional del hábeas corpus -la forma histórica de verificar la legalidad de la detención- e incluso lo que es más importante, en la garantía otorgada por la Quinta Enmienda de que nadie será privado de libertad sin un debido proceso legal. Este principio le niega al gobierno la facultad de encarcelar a una persona sin primero formular la acusación del delito correspondiente y llevarlo a juicio rápidamente. Dicho principio es la fuente de la larga y noble tradición existente en Estados Unidos en contra de la detención preventiva.

Con el paso de los años, se ha reconocido un número limitado de excepciones a la anterior regla: una que se refiere a la comparecencia forzada de testigos clave, otra que permite la reclusión civil de una persona que representa un daño para sí mismo o para la sociedad y una tercera -de especial significado en el contexto de este documento- que busca dar cabida a las exigencias de la guerra. Por imperativos de necesidad, se puede capturar a los combatientes enemigos en el campo de batalla y mantenerlos bajo reclusión mientras duren las hostilidades.

En medio de las operaciones de combate en Afganistán, el Presidente declaró que los soldados de los talibanes y de Al Qaeda detenidos no eran prisioneros de guerra comunes y corrientes, sino que combatientes enemigos ilegales. Según el gobierno, esta designación especial elimina para estos detenidos la protección que otorga la Tercera Convención de Ginebra a los prisioneros de guerra y faculta a los militares para interrogarlos en forma prolongada; permite, además, encarcelarlos indefinidamente, incluso más allá del fin de las hostilidades; además de permitir que se los juzgue y castigue por el solo hecho de combatir. Tradicionalmente, la designación de combatiente ilegal se había aplicado principalmente y en forma individual a espías, saboteadores y civiles que portaban armas en contra de la nación, jamás -como quiere el Presidente- a ejércitos completos.

La primera vez que la política de detenciones del gobierno se puso en cuestión fue durante el proceso de John Walker Lindh, un joven estadounidense capturado en Afganistán que reconoció haber luchado del lado de los talibanes, pero negó haber tenido contacto alguno con AI Qaeda. Citando la regla histórica de que el hecho de combatir no constituye un delito, Lindh presentó una moción pidiendo que se desestimara la acusación de conspiración para asesinar a ciudadanos estadounidenses. El juez de distrito denegó la moción basándose en la teoría de que Lindh era un combatiente enemigo ilegal porque había luchado a favor de los talibanes. A pesar de que 
el juez señaló que no estaba acatando ciegamente la categorización del Presidente, su decisión sugiere lo contrario. En efecto, le traspasó a Lindh el peso de la prueba de demostrar que no era un combatiente ilegal y se basó parcialmente en pruebas inadecuadas -un libro escrito antes de la guerra en el cual se señala que los talibanes accedieron al poder mediante el asesinato de civiles- para decidir que los soldados de los talibanes estaban correctamente clasificados como combatientes ilegales. Una vez denegada la moción de desestimar la acusación, Lindh se declaró culpable de una acusación menor y actualmente cumple una sentencia de 20 años de reclusión en una cárcel federal. El gobierno se reservó el poder de retenerlo como combatiente enemigo ilegal en caso de que la sentencia anterior fuera dejada sin efecto.

Los prisioneros de Guantánamo -todos ciudadanos extranjeros- también han sido tratados como combatientes enemigos ilegales. Se creó una cárcel en la Base Naval de Guantánamo en enero del 2002 y, a pesar de que los sospechosos de pertenecer a Al Qaeda que fueron capturados en un gran número de países -entre ellos Bosnia, Tailandia y Zambia- han sido encarcelados en ese lugar en los últimos años, Guantánamo es, antes que todo, una prisión para personas capturadas durante la guerra con Afganistán. En un momento, llegó a tener hasta 800 prisioneros; a la fecha, siguen allí más de 200. Algunos de estos reclusos niegan haber portado armas en contra de Estados Unidos o tener vínculos con Al Qaeda o incluso con los talibanes, e insisten en cambio que estaban en Afganistán o en la zona fronteriza por razones personales.

En junio del año 2008, la Corte Suprema manifestó que, como materia constitucional, los prisioneros de Guantánamo tenían derecho a interponer un recurso de hábeas corpus para sustentar su derecho a la libertad. Este fallo fue aclamado calurosamente por la prensa, no obstante lo cual no debemos olvidar el hecho de que en dos ocasiones anteriores -en junio del año 2004 y en junio del año 2006- la Corte hizo todo lo posible por evitar un fallo constitucional sobre este particular. En ambas ocasiones, la Corte Suprema simplemente llegó a la conclusión de que el hábeas corpus regía para los prisioneros de Guantánamo como simple interpretación de las leyes pertinentes. La respuesta del Congreso frente a dichos fallos fue reformar esas leyes -la Ley de Trato de los Detenidos del 2005 y la Ley de Comisiones Militares del año 2006- para excluir la posibilidad de un recurso de hábeas corpus. El fallo de la Corte Suprema del año 2008 determinó que dicha exclusión legal respecto del hábeas corpus era inconstitucional, pero no encaró de manera alguna el sufrimiento de quienes estaban encarcelados injustamente en Guantánamo durante todos estos años. Tampoco señaló cuáles eran los derechos constitucionales substantivos de los prisioneros ni menos limitó de modo alguno la facultad del gobierno de mantener recluidos indefinidamente a aquellos respecto de los cuales se pudiera demostrar que habían luchado a favor de los talibanes o Al Qaeda sobre la base de que son combatientes enemigos ilegales.

El gobierno no se ha conformado con limitar la designación de combatiente enemigo ilegal a las personas capturadas en Afganistán u otros teatros de conflicto armado. La guerra contra Al Qaeda no tiene fronteras y, en consecuencia, el gobierno estadounidense se ha empecinado en que los miembros de Al Qaeda pueden ser capturados y recluidos en calidad de combatientes ilegales dondequiera que se encuentren, incluso en Estados Unidos. En virtud de esta política, el gobierno arrestó a un ciudadano de Qatar que estudiaba en Bradley University en Illinois (Ali Saleh Kahlah al-Marri) creyendo que se trataba de un efectivo de Al Qaeda, supuestamente un agente inactivo. Actualmente, está recluido en calidad de combatiente enemigo ilegal en un bergantín naval en Carolina del Sur y ha iniciado un procedimiento de hábeas corpus para obtener su libertad. En forma similar, un ciudadano estadounidense (José Padilla) fue arrestado en el Aeropuerto Internacional de O'Hare en Chicago y recluido en el mismo bergantín durante más de 3 años antes de ser acusado de un delito en un tribunal federal. 
En el caso de Padilla, la Corte Suprema tuvo dos oportunidades para tomar conocimiento de su demanda de libertad y, en ambos caso, no lo hizo. La primera vez, la Corte simplemente señaló que Padilla tendría que haber presentado su petición de hábeas corpus en Carolina del Sur en lugar de hacerlo en Nueva York, a pesar de que el error aducido no tenía vinculación alguna con la facultad de la Corte Suprema para considerar su demanda de libertad. En la segunda ocasión, la Corte Suprema se negó a considerar la petición de fondo de Padilla. Presumiblemente, la Corte estimó que la petición era inoficiosa debido a que días antes de que debiera resolver, el gobierno cambió de estrategia y presentó una acusación criminal en contra de Padilla en una corte federal de Florida, aunque tomó la precaución de reservarse la facultad de tratarlo como combatiente enemigo ilegal en el futuro.

La desmesura de las políticas de detención del gobierno representa un grave peligro para la sociedad estadounidense. No se trata de si la lucha contra Al Qaeda constituye una "guerra" sino si Estados Unidos es un "campo de batalla" similar a Afganistán. Tratarlo como tal constituiría una amenaza para el tejido de la vida cotidiana y permitiría que la tradicional excepción al principio de libertad para los combatientes enemigos se tragara al principio mismo. El poder ejecutivo estaría en condiciones de encarcelar a cualquiera que viva entre nosotros -tanto a los ciudadanos como a los no ciudadanos por igual- sin jamás acusarle de un delito ni llevarlo a juicio.

Por último, la guerra contra el terrorismo también ha cuestionado otro principio constitucional arraigado en la Cláusula del Debido Proceso: el principio de un juicio justo. En julio del año 2004, el gobierno creó en Guantánamo un sistema de tribunales, con el nombre de Tribunales de Revisión de la Situación de los Combatientes (Combatant Status Review Tribunals), con el fin de resolver las demandas de los prisioneros recluidos en ese lugar, los cuales afirmaban que su detención era indebida porque no habían combatido a favor de los talibanes o Al Qaeda, ni les habían brindado ayuda sustancial a ninguno de los dos grupos. A pesar de que, con el paso de los años, unos 40 prisioneros han sido liberados por estos Tribunales, los procedimientos por los cuales se rigen constituyen una afrenta a los más elementales conceptos de equidad. Los Tribunales en cuestión son manejados por los militares libres del peso de las tradicionales reglas sobre las pruebas. A los prisioneros se les proporcionan "representantes personales" pero estos no son abogados, sino que sólo militares con rango de oficial y acreditación de seguridad. La ley de diciembre del 2005, en el que se negó a los prisioneros de Guantánamo el derecho a interponer un recurso de hábeas corpus para obtener su libertad, también respaldó este sistema de procedimiento y le otorgó a la Corte de Apelaciones de Estados Unidos correspondiente al Circuito de D.C. jurisdicción exclusiva para revisar las decisiones de los Tribunales de Revisión de la Situación de los Combatientes. Aun así, restringió el campo de revisión del tribunal a un reducido número de cuestiones procesales.

A pesar de que todos los prisioneros que están en Guantánamo se encuentran recluidos en forma indefinida y han sido sometidos a interrogatorios persistentes y agresivos, algunos soportan la carga adicional de haber sido acusados de crímenes de guerra y sometidos a juicio ante comisiones militares. Dichas comisiones se distinguen de las cortes marciales y las cortes federales en la medida que son convocadas para objetivos circunscritos -juzgar a algunos de los prisioneros de Guantánamo- y que deben ceñirse a normas procesales diseñadas especialmente para lo que se percibe como las necesidades que impone la guerra contra Al Qaeda.

En junio del año 2006, la Corte Suprema determinó que estas comisiones no eran legales aunque sólo sobre la base de fundamentos extremadamente limitados. Como punto inicial, la Corte Suprema señaló que, en el pasado, las comisiones militares habían sido tribunales de necesidad utilizados principalmente para juzgar a personas "capturadas in fraganti en el teatro de guerra". La Corte entendió que las comisiones de Guantánamo no calzaban con esta caracterización, ya que algunos 
de los prisioneros sometidos a juicio llevaban más de cuatro años encarcelados en Guantánamo, y formuló una advertencia en contra de convertir a las comisiones militares, transformándolas "de un tribunal de verdadera necesidad, a una herramienta adjudicatoria de conveniencia". No obstante, la Corte evitó resolver sobre puntos de debido proceso, limitándose a señalar que las comisiones militares de Guantánamo violaban una disposición del Código Uniforme de Justicia Militar que requiere que todas las normas y reglamentos de las cortes marciales y las comisiones militares sean "uniformes en la medida que sea factible".

Como apoyo para esta conclusión, la Corte señaló que, a diferencia de los procedimientos para las cortes marciales, las normas que regían las comisiones en Guantánamo permitían que el acusado quedara excluido de los procedimientos o se le negara acceso a las pruebas utilizadas en su contra en una amplia gama de circunstancias. La Corte agregó que las comisiones operaban conforme a normas de evaluación de la prueba más permisivas que las que regían para las cortes marciales y que aparentemente, en la práctica admitían pruebas obtenidas bajo coacción. La Corte también señaló su preocupación de que el acusado no tuviera derecho a apelar de su condena ante una corte civil, excepto en casos de la pena capital o una pena de cárcel superior a diez años. Tratándose de penas inferiores a las anteriores, el conceder el recurso de apelación quedaba sujeto a la discreción del Tribunal de Revisión.

En último término, sin embargo, la Corte Suprema se abstuvo de decidir sobre cuestiones constitucionales y señaló que el Presidente había violado las disposiciones legales al exigir que los procedimientos empleados por la comisión fueran lo más parecidos posible a los de las cortes marciales. El hecho de restringir el alcance de su fallo de tal manera, tuvo el efecto perverso de poner los valores fundamentales en mayor peligro. En respuesta al fallo de la Corte, el Congreso aprobó la Ley de Comisiones Militares del 2006, que reafirmó la prohibición de peticiones de hábeas corpus de parte de los prisioneros de Guantánamo y otorgó al gobierno la facultad de utilizar las comisiones militares para juzgar a dichos prisioneros. Las protecciones procesales de los acusados fueron ampliadas solamente en algunos aspectos. Actualmente, los juicios en Guantánamo se realizan ante comisiones militares. La Corte Suprema rechazó todo intento por impugnar la corrección de los procedimientos, al menos una vez realizado el juicio, emitido el fallo y tramitadas las apelaciones.

Los prisioneros de Guantánamo constituyen un grupo particularmente vulnerable. La Constitución le garantiza un debido proceso a "toda persona", pero ha habido argumentos en el sentido de que los extranjeros no están cubiertos por la protección de la Constitución, particularmente si no están recluidos en territorio soberano de Estados Unidos. Es notable, sin embargo, que la Corte haya aminorado los requisitos del debido proceso incluso para los ciudadanos estadounidenses. El caso más notorio en este sentido, fue una decisión tomada en el 2004 respecto de un ciudadano estadounidense, Yaser Esam Hamdi, que había sido aprehendido en Afganistán y encarcelado en un bergantín naval en Norfolk, Virginia. El gobierno afirmó que el prisionero había luchado de parte de los talibanes y por lo tanto era un combatiente enemigo ilegal. Su padre (que presentó la demanda) negó dicha acusación e insistió en que su hijo había ido a Afganistán en agosto del año 2001 con el fin de prestar ayuda humanitaria.

En su voto, la Jueza O'Connor dictaminó que "un estado de guerra no es un cheque en blanco para el Presidente cuando se trata de los derechos de los ciudadanos de la Nación" y en ese sentido sostuvo que el prisionero tiene derecho a una audiencia de prueba para rebatir las acusaciones del gobierno. La Jueza señaló, asimismo, sin entrar en detalles, que el prisionero tiene derecho a asesoría legal en tales procedimientos. No obstante, a continuación, la Jueza O’Connor insistió en que los derechos procesales de los prisioneros debían ser "adaptados cuidadosamente para aliviar la carga potencial y poco común que representan para el Poder 
Ejecutivo en momentos en que hay un conflicto militar en curso". En consecuencia, la Jueza O'Connor permitió que el gobierno apoyara su afirmación de que un prisionero es un combatiente enemigo mediante la presentación de prueba basada en los registros que llevan los militares sobre los detenidos en el campo de batalla. Dicha prueba generaría la suposición, señaló la Jueza O'Connor, que el prisionero sería un combatiente enemigo. Recaería sobre el prisionero, en consecuencia, la carga de la prueba de rebatir la presunción y demostrar que no es un combatiente enemigo. De este modo, $\mathrm{O}^{\prime}$ Connor nominalmente le negó el "cheque en blanco" al gobierno junto con acceder, no obstante, a su demanda de deferencia en asuntos relacionados con la seguridad nacional.

La Jueza O'Connor también manifestó la opinión -que no fue respaldada por la mayoría en este caso- de que una comisión militar podía proporcionar la audiencia de prueba que ella exigía. Esta concesión es perjudicial para el debido proceso que, durante largo tiempo, ha sido considerado como una instancia que requiere de un responsable de las decisiones que sea imparcial o neutral, incluso cuando son solo los derechos de propiedad los que se encuentran bajo amenaza de parte del gobierno. La opinión también hace caso omiso de los fundamentos constitucionales de las peticiones de libertad de los prisioneros y de la necesidad de realizar una audiencia de prueba en un tribunal federal de hábeas corpus no meramente porque dicho tribunal puede lograr la imparcialidad requerida sino también -lo que es más fundamental- porque en el esquema constitucional de Estados Unidos, el poder judicial federal es el responsable de determinar si una persona ha sido privada de un derecho garantizado por la Constitución, como sucede con el derecho a la libertad.

En resumen, la guerra contra el terrorismo ha tenido un costo considerable para nuestra Constitución: la prohibición contra la tortura ya no parece tan sacrosanta; se han instituido las intervenciones de teléfonos sin requerir una orden judicial; la norma que prohíbe la detención preventiva ha sido violada en el caso de aquellos que han tenido la poca fortuna de ser calificados como combatientes enemigos ilegales; se ha ampliado en gran medida el alcance de las comisiones militares; y las garantías procesales para tramitar las peticiones de libertad-incluso aquellas presentadas por ciudadanos estadounidenses- han sido disminuidas. A pesar de que muchas personas han denunciado este distanciamiento respecto de nuestra tradición constitucional, tales denuncias, en su mayoría, implican que se han cometido excesos por un solo Presidente y su gobierno. La tendencia a asignar culpas por este cuadro de ilegalidad se ha exagerado en gran medida en estos días conforme avanza la carrera presidencial del 2008, y se anticipa un cambio en la Casa Blanca. Mi perspectiva es diferente.

Ciertamente, el Presidente ha tenido la iniciativa. El inició las políticas que han puesto en peligro los valores constitucionales, no obstante lo cual el Congreso reiteradamente se manifestó muy dispuesto a respaldar dichas políticas. En la Ley de Trato de los Detenidos del año 2005, el Congreso reformó la ley de hábeas corpus con el objeto de denegarles ese recurso a los prisioneros de Guantánamo y dar su apoyo legal a los procedimientos rudimentarios establecidos para juzgar la demanda de libertad de los prisioneros de Guantánamo. En la Ley de Comisiones Militares del año 2006, el Congreso autorizó plenamente a las comisiones militares para que juzgaran a los prisioneros de Guantánamo, así como a cualquier extranjero calificado de combatiente enemigo ilegal. En las enmiendas a la FISA en junio de 2008, el Congreso autorizó la intervención telefónica sin órdenes judiciales en casos similares a los que cubre el Programa NSA original. Una excepción notable es la Ley de Trato de Detenidos del año 2005 que, a pesar de las objeciones del Presidente, reafirmó la prohibición de la tortura, vedando esta práctica por parte de todo el personal estadounidense que operara en cualquier lugar y en contra de cualquier persona. Sin embargo, incluso esta legislación no logró proporcionar a las víctimas de tales abusos un medio 
para proteger sus derechos y, en la práctica, denegó el recurso de hábeas corpus a un grupo que corría serias posibilidades de ser torturado: los prisioneros de Guantánamo.

El Poder Judicial también ha sido cómplice en este ataque contra la legalidad. Los jueces federales se han negado a ver todas las causas presentadas por personas que afirman haber sido sometidas a una rendición extraordinaria, incluso bajo el supuesto de que las acusaciones fueran verdaderas. Los jueces han insistido en que toda investigación respecto de los méritos de sus demandas, pondría en peligro "secretos de Estado". El juez del caso Lindh respaldó la política presidencial de tratar a todos los soldados de los talibanes como combatientes enemigos ilegales, sujetos, en consecuencia, a una detención sin fin. La Corte Suprema determinó que los ciudadanos estadounidenses capturados en Afganistán que estaban recluidos en calidad de combatientes enemigos tenían derecho a una audiencia de prueba respecto de su demanda de libertad, pero en última instancia se diluyeron los requisitos del debido proceso. En otros casos, la Corte no cumplió con su responsabilidad elemental de proteger la Constitución al desechar casos, tales como el de los prisioneros de Guantánamo o incluso el de un ciudadano estadounidense (José Padilla) sobre la base de estrechos tecnicismos; ello dio pie a sucesivos recursos judiciales, retardos procesales e intervención del Congreso, lo cual solo sirvió para corregir los defectos técnicos en la legislación identificados por la Corte.

Desde este punto de vista, lamento decir que sería un error esperar gran cosa del próximo gobierno. El daño ya fue cometido y un cambio total de orientación es poco probable. Algunos gestos de gran visibilidad, como el cierre de Guantánamo -que cuenta con el respaldo tanto del Senador Obama como del Senador McCain- podrían Ilegar a realizarse, pero las políticas que tienen el apoyo del Congreso, que la Corte Suprema deliberadamente ha rehusado examinar, tales como el hecho de recurrir a comisiones militares y la intervención de teléfonos sin mediar una orden judicial para fines de seguridad nacional, seguirán en pie. Están demasiado afianzados. Las instituciones no cambian de rumbo con facilidad, incluso cuando cambia su personal. Las expectativas han sido redefinidas y quienes insisten en un retorno a la Constitución se encontrarán con la carga que conlleva el statu quo, reforzado por los recuerdos del 11 de septiembre y los temores que dichos recuerdos engendran. 
